\title{
A New Theoretical View of Rockburst and Its Engineering Application
}

\author{
Junfeng Pan (i), Shaohong Liu, Shuwen Wang, and Yongxue Xia
}

Mining and Designing Branch, China Coal Research Institute, Beijing 100013, China

Correspondence should be addressed to Junfeng Pan; panjunfeng@yeah.net

Received 5 January 2018; Accepted 12 April 2018; Published 16 August 2018

Academic Editor: Qianbing Zhang

Copyright (c) 2018 Junfeng Pan et al. This is an open access article distributed under the Creative Commons Attribution License, which permits unrestricted use, distribution, and reproduction in any medium, provided the original work is properly cited.

\begin{abstract}
Traditionally, rockburst is considered as a dynamic phenomenon of sudden destruction of coal/rock mass. In this study, rockburst is treated as an event process rather than a phenomenon. This paper introduces typical rockburst process, its classification, mechanism of internal and external causes, and energy criterion. Analysis indicates that rockburst is a dynamic process that includes three sequential phases: burst start-up, burst energy transfer, and rockburst pressure behavior. Excessive static stress concentration in the strata nearby the target zone appears to be the internal cause of rockburst start-up, while the external cause is the disturbance of the static stress concentration and additional load transfer by the concentrated dynamic load occurred at further distance. Potential burst start-up area is the highest stress concentration zone within the region where stress is in the critical equilibrium state. With the identified internal and external factors that contribute to rockburst start-up, it is concluded that the rockburst preventive measures should focus on the monitoring and controlling of originating source of static and dynamic stress concentrations. Field practice proves that the reunderstanding of rockburst and the derived preventive measures are feasible and successful.
\end{abstract}

\section{Introduction}

Rockburst is a problem faced by most countries in the world [1-6]. The mechanism of rockburst could be a base to effectively monitor and prevent the mine rockburst. From an initial record of the mine rockburst phenomenon to the present in the world, there was a history of 274 years [7-11], and during the period, "strength theory," "rigidity theory," "energy theory," "burst potential theory," "instability theory," and other theories were formed [12-17]. Those theories all revealed that the condition and principle of the mine rockburst occurred from different flanks and would play a due promotion role in the study on the mine rockburst. Nevertheless, the present monitoring and prevention technologies of the mine rockburst are still seriously divorced from the mechanism. As the present public understanding of the mine rockburst is an integrated conception, or would highly outweigh the postdisaster result phenomenon and lack an analysis on the occurred process, it would be hard to reveal a time sequence and the correspondence space sequence of the rockburst occurred; hence, the whole rockburst process could not be clearly explained, and it would be hard to guide the application target and opportunity of the monitoring and prevention technology.

This paper analyzed the evolution process of the mine rockburst and reclassified the type of the rockburst. In combination with the study on the mine rockburst mechanism and the engineering structure, a burst start-up theory was provided and a packaged applied technology of the local rockburst prevention was set up based on the burst start-up theory. Thus, the concentrated static load-type and concentrated dynamic load-type mine rockburst prevention ideas would be clear, and the effect would be fast.

\section{Evolution Process of Rockburst}

At present, the public understanding of the mine rockburst was the same as presented in Figure 1. Only knowing the input on the certain geological and mining conditions, a certain sudden output would be a disaster occurred with no knowledge of the middle process, and this would be the understanding of the typical "black box." The mine rockburst occurred would be in seconds generally. But as an event, there would be a self-occurred stage generally. 


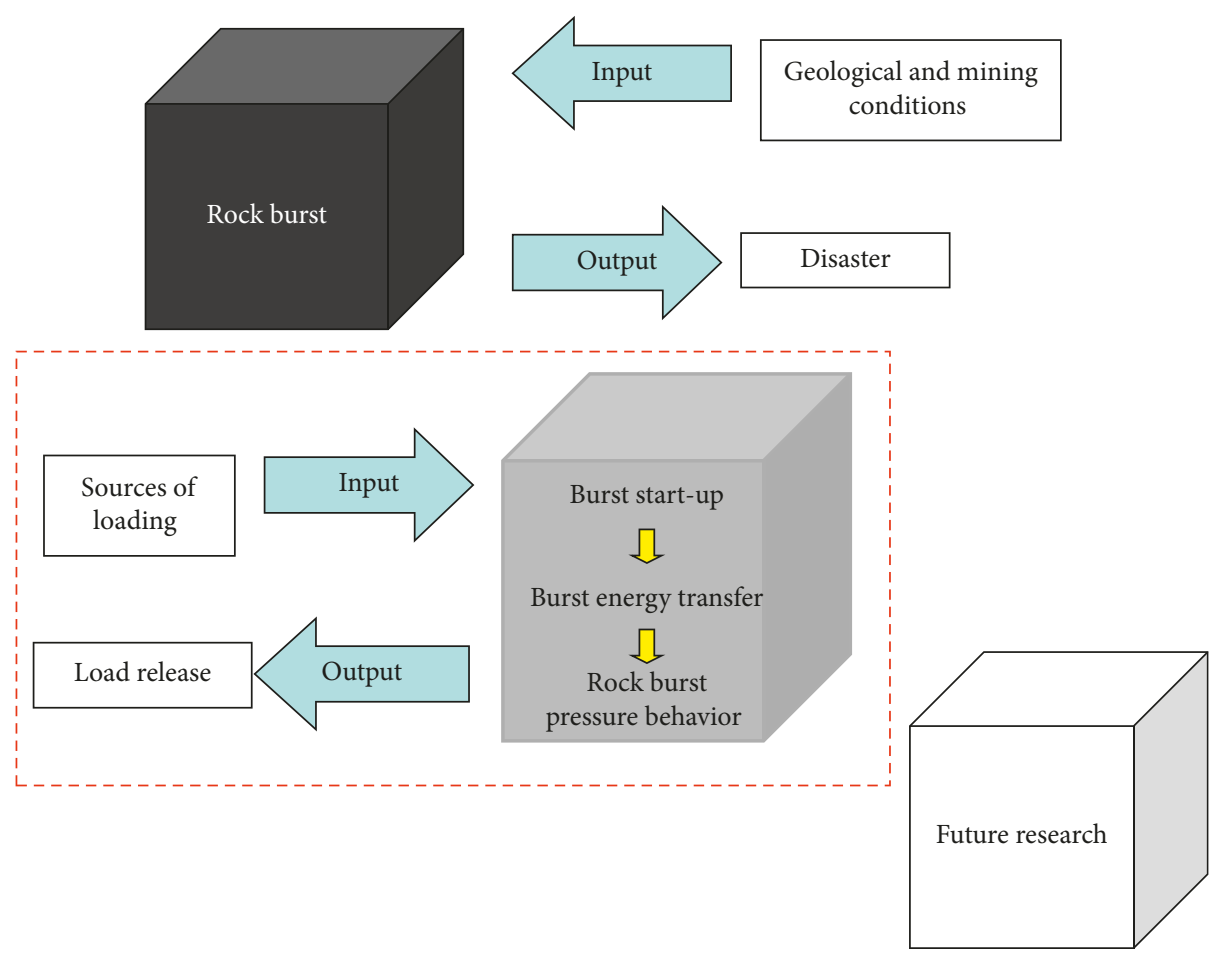

FIGURE 1: Black box understanding of the rockburst process.

In addition, the materialist dialectics said that the world is a material world and the material is in motion. But, the time and space are the two basic forms of the material movement. Theoretically, a time axis and a space axis could be applied to a stage landmark position on the whole evolution process of the event, and thus the time and space process of the whole event occurred. Temporarily, this paper only discussed the time sequence of the occurred mine rockburst. What we usually see with naked eyes is the state after rock burst, which is mainly manifested in casualties, equipment damage, road failures, and so on. For this reason, we define the result state after the occurrence of rock burst as the rock burst appearance, that is, the final stage in the process of rock burst. Virtually before the last stage, there were other two stages.

The location of the coal/rock strata fractured event positioned with the microseismic was always far from the location of the actual mine rockburst behavior. A high-stress zone measured in the surrounding rock finally would not be in a region of the mine rockburst behavior but shown during the mine rockburst occurred process, and a different rockburst behavior zone existed. This paper made a coal/rock-fractured zone with a leading role at the rockburst behavior stage defined as a rockburst start-up zone. Meanwhile, the first stage in the relevant rockburst occurred process was the rockburst start-up stage.

Energy measured with the microseismic was specially high and was over $10^{8} \mathrm{~J}$. But, the actual mine rockburst behavior was not serious and could not cause a large damage. Sometime, the energy positioned was small, and the mine rockburst behavior was very serious. Therefore, there was a certain energy transfer process from the rockburst start-up to the rockburst behavior stage; the transfer process could cause an attenuation of the energy, and this would be the second stage in the rockburst occurred process and a rockburst energy transfer stage.

Thus, the paper held that the rockburst occurred would undergo three stages, and they were rockburst start-up, burst energy transfer, and rockburst behavior. The understanding of the rockburst was the same as shown in Figure 1 and was in the "gray box" stage. To conduct this study, the rockburst start-up was the key point of the paper, and the focus of the rockburst prevention and study could be advanced to the first stage.

\section{Classification of Rockburst}

A statistics method was applied to the search on the academic papers from 2002 to 2014, and there were 367 related papers searched. Those papers concluded and analyzed the main influence factors of 67 mine rockbursts occurred recently in China [18].

The geological influence factors would mainly include hard and thick roofs, overburden high-level thick rock stratum, hard floor, geological structure, high inclination, seam thickness variation, and natural seismic. The mining technical factors would mainly include island coal pillar formed in a same seam mining, the overburden coal pillar formed under the seam group mining, and the blasting vibration.

Although the above factors are complex and changeable, in essence, they provide two kinds of loads for rock burst. Therefore, from a view of the rockburst start-up, the rockburst could be mainly divided into 2 types, which are concentrated static load and concentrated dynamic load. 
The concentrated static load-type rockburst occurred would have the main features of the stress with slow migration, concentration, and steady loading. The main influence factors would include the following: (i) the mining depth increased caused gravity stress to increase, (ii) the historical structure movement caused the horizontal structure stress to increase, (iii) adjacent or same directional mining and island pillar caused the support pressure to overlay, (iv) the coal mining in advance or the gateway side supported pressure to concentrate, (v) the variation of the seam thickness caused local seam to become thinner or a pinchout caused the stress to concentrate, (vi) the fault caused the footwall and upperwall stress to concentrate in the fractured zone, and (vii) the mining or driving speed too fast caused coal/rock stress to not adjust properly.

The concentrated dynamic load meant the sources relatively concentrated and a rockburst load with a short time rapid role. A concentrated dynamic load-type rockburst occurred would have the main features with the pulse load or elastic wave-loading mode, and the main influence factors would include the following: (i) large area suspended roof broken and displacement in the goaf of the coal mining face, (ii) the suspended roof broken caused by the great coal pillars recovered, (iii) "activation" of the fault near the coal mining face, (iv) the vibration waves caused by the blasting operations in the underground mine, and (v) the disturbances caused by the natural seismic.

\section{Rockburst Start-Up Theory}

4.1. Engineering Structure Model and Energy Criterion. From a view of the minefield scope, the mine rockburst generally occurred in a local area. Based on the statistical results of 67 mines in the recent 12 years, the rockbursts mainly occurred in the mining gateway, gateway driving face, and coal mining face. Therefore, the engineering structure models of the two rockburst types were established, and a study was conducted on the rockburst start energy condition and the engineering structure combined.

4.1.1. Concentrated Static Load-Type Rockburst Start Energy Criterion. The engineering structure model of the concentrated static load-type rockburst is shown in Figure 2. After the gateway excavated, the vertical stresses of the two sidewalls would have the features shown in Figure 2.

Under the triaxial stress state of the generalized Hook's theorem, a calculation formula of the coal elastic strain energy was

$$
E_{0}=\frac{\left[\sigma_{1}^{2}+\sigma_{2}^{2}+\sigma_{3}^{2}-2 \mu\left(\sigma_{1} \sigma_{2}+\sigma_{1} \sigma_{3}+\sigma_{3} \sigma_{2}\right)\right]}{2 E},
$$

where $E$ is the elastic modulus, $\mu$ is the Poisson ratio, and $\sigma_{1}, \sigma_{2}, \sigma_{3}$ are the main stress.

From formula (1), if the coal/rock mass was rated, $E$ and $\mu$ were rated. Therefore, the elastic strain energy stored in the study zone was closely related to the main stress size in the

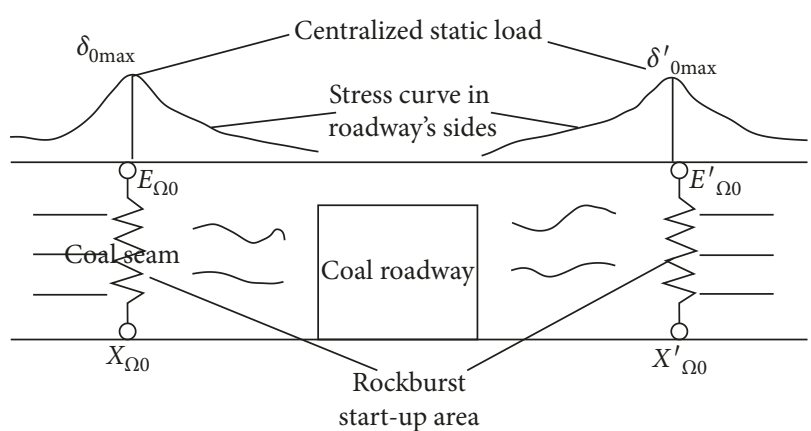

FIGURE 2: Engineering structure model of concentrated static loadtype rockburst.

location; that is, the elastic strain energy stored in the each stress location of the gateway surrounding the rock would be different. The surrounding rock stress could be applied to divide the elastic energy storage of the two sidewall surrounding rock of the gateway.

As shown in Figure 2 (where $\delta_{0 \max }$ was the stress peak of the surrounding rock, $X_{\Omega 0}$ was the limit equilibrium zone of the gateway sidewall, and $E_{\Omega 0}$ was the elastic strain energy loaded in the zone), the coal/rock stored energy and the stress concentration coefficient were increased in a nonlinear tendency, the $E_{\Omega 0}$ at the $X_{\Omega 0}$ was a maximum value of the elastic strain energy in each zone of the gateway surrounding the rock, and thus the $X_{\Omega 0}$ zone was the main loading area of the gateway sidewalls and shown with a spring in Figure 2. According to the minimum energy principle of dynamic failure of rock mass [19], the main bearing area of roadway side coal body is destroyed by uniaxial compression or shear mode, and the condition of its failure is that the stress exceeds the uniaxial compression strength or shear strength. A correspondence energy consumption criterion would be as the following:

$$
\begin{aligned}
& E_{\mathrm{c}}=\frac{\sigma_{\mathrm{c}}^{2}}{(2 E)} \text { or } \\
& E_{\mathrm{c}}=\frac{\tau_{\mathrm{c}}^{2}}{(2 G)} .
\end{aligned}
$$

Therefore, the $X_{\Omega 0}$ location of the stress peak zone in the gateway was obtained, and the energy condition of the rockburst start was that the concentrated load was steadily increased at the $X_{\Omega 0}$ location. When the accumulated elastic strain energy at the $X_{\Omega 0}$ location was higher than a minimum energy required by the coal/rock failure at the $X_{\Omega 0}$ location, a burst-type failure would start up at the $X_{\Omega 0}$. The impact energy remaining after the start is transferred to the roadway space by the shallow coal as the medium and the carrier and enters the stage of the impact ground pressure; thus, the whole process of the rock burst is completed. Therefore, the mine rockburst start energy criterion established was

$$
E_{\Omega 0}-E_{\mathrm{c}}>0 \text {, }
$$

where $E_{\Omega 0}$ could be calculated with the three main stresses at the $X_{\Omega 0}$ location. 
4.1.2. Concentrated Dynamic Load-Type Rockburst Start Energy Criterion. The engineering structure model of the concentrated dynamic load-type rockburst is shown in Figure 3. In Figure 3, the rockburst occurred at the side of the mining wall in the coal mining face and the rockburst start was affected by the stress concentration of the coal sidewall and the overburden hard roof fell and broke in the coal mining face. Among them, the concentrated static load $E_{0}$ in the limit equilibrium zone of the coal wall in the coal mining face was calculated with formula (1). Because the suspended roof of the overburden roof caused the stress to highly concentrate in the zone, the limit equilibrium zone of the coal wall in the coal mining face would have a maximum elastic energy stored and an easily met instability and failure condition and would be a most sensitive region response to the external dynamic load. But the external dynamic load should be based on the static load concentration of the region and should disturb and load to complete the rockburst start. The energy $E_{\mathrm{d}}$ to transmit the roof broken elastic energy to the limit equilibrium zone of the coal wall shown in Figure 3 was calculated with the following formula:

$$
E_{\mathrm{d}}=E_{\mathrm{d} 0} R^{-\eta}
$$

where $E_{\mathrm{d} 0}$ is the initial energy released from the roof broken and could be measured with the microseismic, $R$ is the distance between the roof broken location and the limit equilibrium zone of the coal wall and could be obtained with the microseismic position and calculation, and $\eta$ is the energy attenuation index when elastic wave transmitted in the coal/rock medium.

Therefore, the limit equilibrium zone of the coal wall was obtained and the start energy condition of the rockburst was that the accumulated elastic strain energy of the limit equilibrium zone plus the dynamic load energy from the roof broken was higher than a minimum energy required for the coal/rock failure in the zone. Thus, the start energy criterion of the mine rockburst established was

$$
E_{0}+E_{\mathrm{d}}-E_{\mathrm{c}}>0 \text {. }
$$

4.2. Rockburst Start-Up Theory. A study on the cause of the rockburst formation would be hard to set up a linear or a serious constrictive relationship for the one directional study. This paper introduced a "system" view of the rock mechanic academia to study the start-up of the mine rockburst. This paper defined the two sidewalls of the gateway and the limit equilibrium zone of the surrounding rock in the coal wall of the coal mining face as a "close to the coal mining face region" with a correspondence concentrated static load distribution. The area beyond the limit equilibrium zone defined as a "far from the coal mining face region" with a correspondence concentrated dynamic load distribution.

Therefore, the energy sources of the rockburst start-up would be mainly divided into two types, which were the concentrated static load of the mining surrounding rock near the coal mining face and the concentrated dynamic load far from the coal mining face. The concentrated static

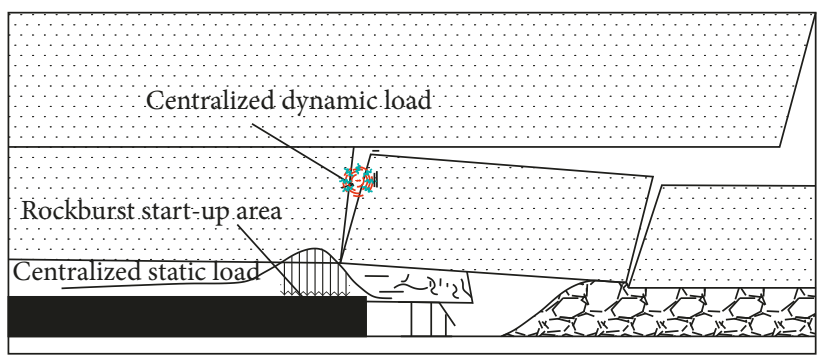

FIGURE 3: Engineering structure model of concentrated dynamictype rockburst.

load mainly included the concentrated compressive elastic energy in the mining surrounding rock and the concentrated bending elastic energy occurred before the roof and floor (strata) bending broke mainly. The concentrated dynamic load would be including the burst waves occurred by the strata activities near or far from the coal mining face, mining and excavation blasting, and others as well as the instantaneous concentrated compressive elastic energy mainly occurred from the large area direct hard roof broken in the coal mining face or overburden highlevel hard roof breaking, floor breaking, and underground mine blasting.

The analysis of the rockburst start-up energy criterion of the two typical engineering structure models showed that the energy to promote the rockburst start-up would be a concentrated static load and could be a concentrated dynamic load. Fundamentally, the concentrated static load should be in the critical condition. That was to say that the concentrated dynamic load was involved and should assist the concentrated static load to reach the critical condition. If the concentrated static load was insufficient, the energy of the dynamic load far from the coal mining face transmitted to the static load concentrated zone would be consumed and a rockburst start-up would be hard to be completed.

Considering the aforementioned points, a rockburst start-up theory was provided in this paper. This paper held that the occurrence of rock burst is a dynamic process, which follows 3 stages: shock initiation, impact energy transfer, and rock burst. The concentrated static load accumulation in the mining surrounding the rock near the coal mining face would be the internal factor of the rockburst start, and the concentrated dynamic load far from the coal mining face to the disturbulence and load of the static load would be the external cause of the rockburst start-up. A possible rockburst start-up zone would be the stress peak maximum zone of the limit equilibrium zone, and the energy criterion of the rockburst was $E_{\text {static }}+E_{\text {dynamic }}-E_{\mathrm{c}}>0$.

\section{The Engineering Application of Rockburst Start-Up Theory}

5.1. Theory and Technical System of Rockburst Prevention. The theory and technical system of the local rockburst prevention in mining and driving space is established and shown in Figure 4. 


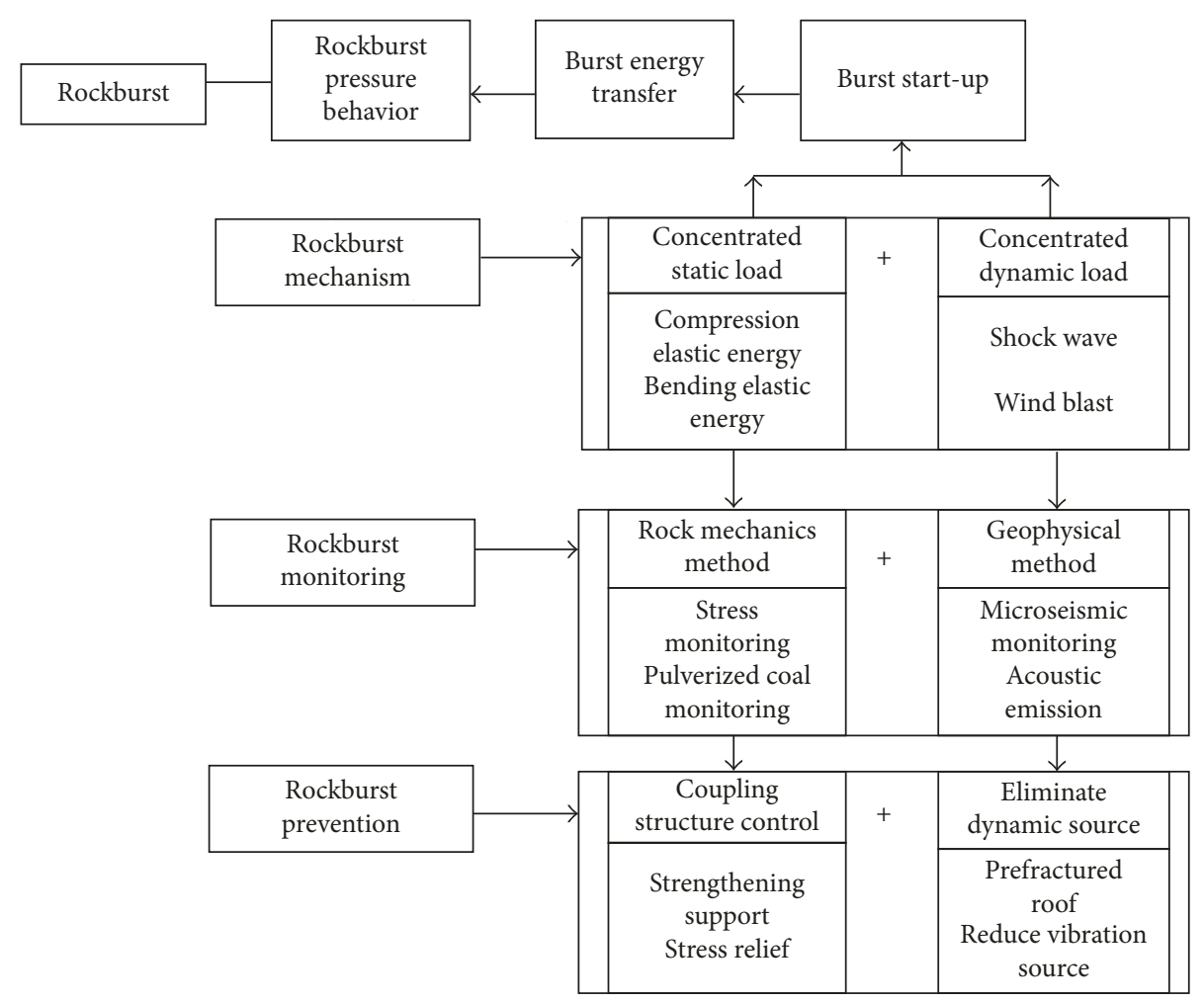

FIgURE 4: Theory and technical system of local rockburst prevention.

The certain implemented method:

(i) As shown in Figure 4, in a mine with rockburst in potential, the rockburst start-up condition should firstly be determined and the concentrated static load sources of the mining surrounding the rock near the coal mining face should be clarified. What are the sources of far-field concentrated dynamic loads of mining surrounding rocks? Which load plays the leading role?

(ii) According to the analysis results of the rockburst mechanism, a monitoring and measuring on the rockburst start-up load sources should be conducted. A rock mechanic method would be applied to monitor and measure the concentrated static load of the mining surrounding the rock near the coal mining face. A geophysical method would be applied to monitor and measure the concentrated dynamic of the mining surrounding rock far from the coal mining face.

(iii) According to the source monitoring and measuring results of the rockburst load sources, related prevention was conducted. According to the high accumulation of the static load, a coupling structure control method was applied to the rockburst prevention. In the rockburst danger zone, a pressure releasing between the deep boreholes would be conducted mainly and a powerful support of the surrounding rock would be auxiliary. The "pressure releasing" and "powerful support" coupling structure in the surrounding rock near the coal mining face could promote a coordinative deformation in the limit equilibrium zone of the surrounding rock and could control the rockburst disaster occurred. As for the concentrated dynamic load source occurred, a one by one source elimination method was applied to prevent the rockburst occurred. According to the monitoring and measuring position results, a roof and floor prefracturing blasting was conducted in advance and a blasting volume in the same time and in the same region should be reduced.

In the above system, once the rock burst was started, the support and other methods would be mainly used to intercept and reduce disasters in the latter two stages. The role of the work conducted would be limited, and thus the key would be at the rockburst start-up stage.

\subsection{Application Cases of Theory and Technical System}

\subsubsection{Prevention of Concentrated Static Load-Type Rockburst}

(1) Analysis on Load Source of Rockburst Start-Up. The seam inclination in Gushan Mine was $26^{\circ}$ in average, the average thickness was $14 \mathrm{~m}$ and the seam would have a weak rockburst tendency. The maximum roof thickness of the gateway under the present mining block was $232 \mathrm{~m}$, uniaxial compressive strength was $147 \mathrm{MPa}$ and the roof would have high rockburst tendency. The floor of the seam was 
sandstone with a thickness of $60 \mathrm{~m}$. No. 069-2 coal mining face was a coal mining face in the mine. The designed strike length of the coal mining face was $400 \mathrm{~m}$, the inclined length was $61 \mathrm{~m}$ and the depth of the haulage roadway was $370 \mathrm{~m}$. The east of the coal mining face was close to the mine boundary, the south of the face was close to no. 068-2 mining goaf in the upper section, the north of the face was close to an undeveloped mining area and the west of the face was a haulage roadway of the mining block as shown in Figure 5. The upper and haulage roadways of no. 069-2 coal mining face both were under no. 068-1 goaf and no. 069-1 goaf.

After the two gateways driving of no. 069-2 coal mining face was completed, when the mining equipment was ready to be installed, on October 17, 2012, a rockburst disaster (Figure 6) occurred in the haulage roadway close to the overburden goaf location. Instantly the gateway with a length of over $70 \mathrm{~m}$ was almost closed. There were 23 miners in operation under the support shield of the mine cars. Finally, there were 13 miners injured and the coal mining face stopped production for three months. The failure caused by the rockburst is shown in Figure 5.

As shown in Figure 7, according to the actual mining condition of no. 069-2 coal mining face, a coal/rock load model of the haulage roadway was established. Based on the site measurement, there was a horizontal stress of $25 \mathrm{MPa}$ in the roof and floor of the haulage roadway. In the vertical direction, the load $F_{\mathrm{M}}\left(G, F_{\mathrm{C}}, N, F_{\mathrm{Q}}, F_{\mathrm{h}}\right)$ of the limit equilibrium zone of the two sidewalls were highly concerned. Among them, $G$ was the dead weight of the overburden strata in the gateway, $F_{\mathrm{C}}$ was the lateral support pressure of the two sidewalls along the gateway, $N$ was the bending elastic energy of the roof in the upper sectional goaf, $F_{\mathrm{Q}}$ was the advance support pressure of the coal mining face, and $F_{\mathrm{h}}$ was the support pressure beyond the open-off cut of the overburdened goaf. Thus, theoretically, $F_{M}$ was the positive related function of the aforementioned parameters. Those parameters were the load sources mainly to provide the bending elastic energy or the compressive elastic energy and would be the concentrated static load.

According to the burst start-up theory of the rockburst, a burst start-up or not in the haulage roadway of the coal mining face would depend on the $F_{\mathrm{M}}\left(G, F_{\mathrm{C}}, N, F_{\mathrm{Q}}, F_{\mathrm{h}}\right)$ function value reaching the limit or not. The depth of the haulage roadway in no. 069-2 coal mining face was converted to a gravitational stresses of $9.25 \mathrm{MPa}$, and the site measured stress concentration coefficient in the zone was 1.7 in average. Thus, the average stress calculated in the zone was 15.73 MPa and was over the seam with a uniaxial strength of $10.51 \mathrm{MPa}$. Meanwhile, the elastic energy at the "10.17" burst behavior point was estimated with the Hooke law and was $45 \mathrm{~kJ} / \mathrm{m}^{3}$. A minimum energy required by the dynamic failure calculation was $E_{\mathrm{c}}=\sigma_{\mathrm{c}}^{2} /(2 E)=15.34 \mathrm{~kJ} / \mathrm{m}^{3}$, and thus $E_{\text {static }}-E_{\mathrm{c}}>0$. Based on the burst start-up theory, a single concentrated static load could cause the burst start-up.

From the theoretical analysis, the principle of "10.17" impact ground pressure was that the lower roof of the short wall working face was still in the flexural elastic energy $N$ covering area. The side high support pressure $F_{\mathrm{h}}$ beyond no. 069-1 goaf in the overburden strata and the lateral support

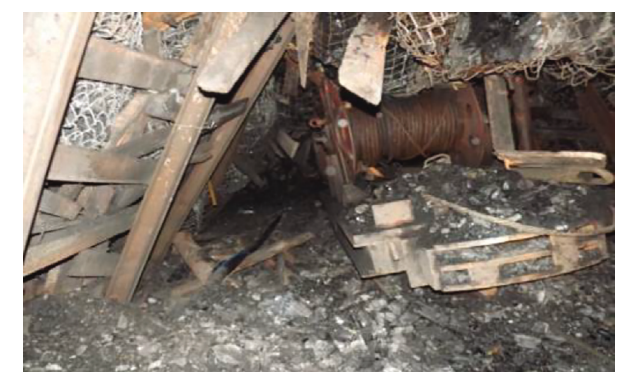

Figure 5: Picture of haulage roadway failure caused by rockburst.

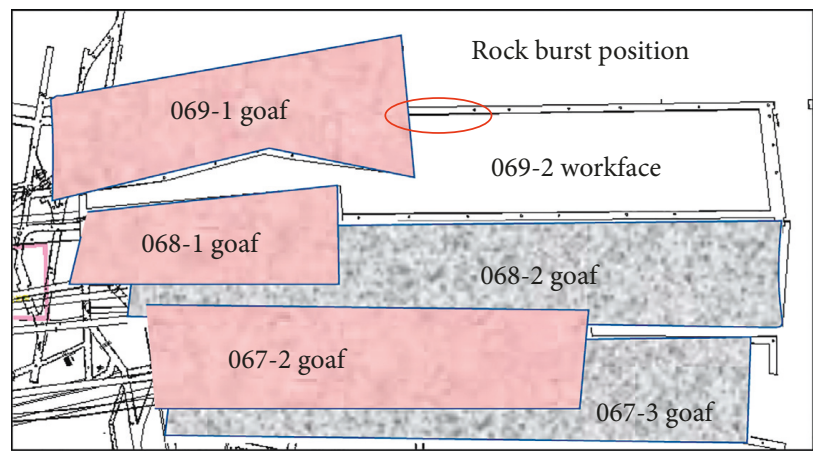

FIgURE 6: Location drawing of coal mining face and rockburst behavior.

pressure $F_{\mathrm{h}}$ of the two sidewalls in the gateway were overlaid. The three force sources under the turbulence of gateway driving were in a positive related relationship to the time $t$. As for the surrounding rock of the two sidewalls in the gateway, the long-term strength and the time $t$ would be a negative related function. Therefore the high function $F_{\mathrm{M}}$ $\left(G, F_{\mathrm{C}(t)}, N_{(t)}, F_{\mathrm{h}(t)}\right)$ of the concentrated static load under a lack of $F_{\mathrm{Q}}$ condition could still meet the burst start-up condition and was called as a concentrated static load-type rockburst. Therefore the late rockburst monitoring and early warning would be based on the study on the concentrated static load evolution law mainly.

(2) Monitoring and Measuring of Concentrated Static Load. As shown in Figure 8, a coal stress online monitoring and measuring system was applied to the stress concentration monitoring and measuring of the sidewalls in the haulage roadway. There were 25 measuring stations set up. Each station would have three measuring points, the measuring depth of the measuring point was $7 \mathrm{~m}, 10 \mathrm{~m}$, and $15 \mathrm{~m}$ individually. There were 75 measuring points in total. The distance between the first measuring station to the entry of the haulage roadway was $10 \mathrm{~m}$, and the distance between each measuring point was $5 \mathrm{~m}$ in average. The depth of the sensor buried in sequence would be $7 \mathrm{~m}, 10 \mathrm{~m}, 15 \mathrm{~m}, 7 \mathrm{~m}$, $10 \mathrm{~m}$, and $15 \mathrm{~m}$.

Figure 9 is the stress nephogram of the low sidewall in the haulage roadway of no. 069-2 coal mining face monitored and measured with the KJ21 rockburst stress online monitoring and measuring system. Figure 9 shows that around the boundary of the goaf in no. 069-1 coal miming face in the top slice seam was a stress high increased region. 


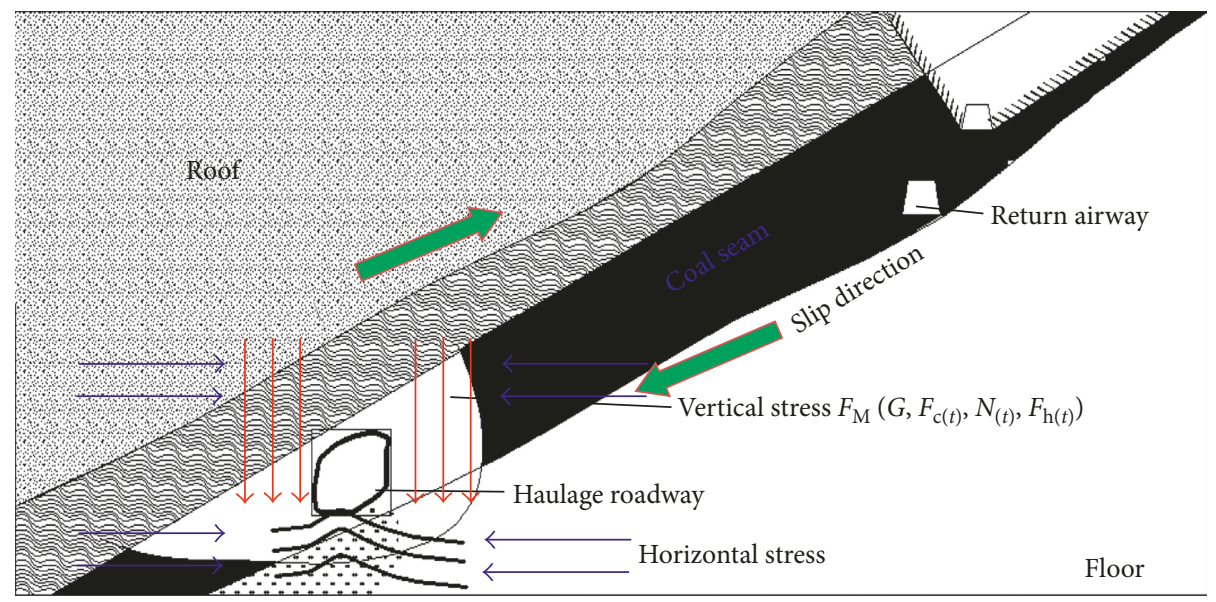

Figure 7: Load diagram of haulage roadway in coal mining face.

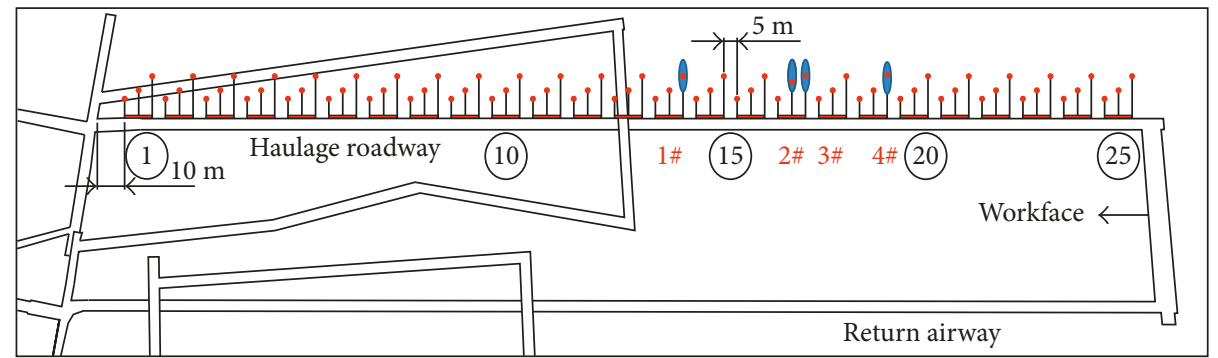

FIGURE 8: Layout diagram of stress online monitoring and measuring system in haulage roadway.

With the advancing of the coal mining face and affected by the advance support pressure, the stress increasing and region would be continuously increased.

With the hard and completed roof strata, no. 069-2 coal mining face was in a stress increased region except for the top slice $068-1$ and $069-1$ goaf and the local location of no. 068-2 coal mining face.

(3) Rockburst Prevention. Except for the powerful support of the high stress zone, a seam blasting was a fast rockburst prevention method to release the pressure. According to the stress nephogram measured by the KJ21 rockburst stress online monitoring and measuring system, when the stress monitoring was near the early-warning value and the area with frequent microseismic events, the method of blasting with deep hole in coal seam is adopted. The engineering diagram is shown in Figure 10.

Blasting Plan. (i) A deep borehole blasting was applied to the two sidewalls of the gateway and the depth designed of the blasting borehole was $20 \mathrm{~m}$. (ii) A space distance between each blasting hole in a same sidewall of the gateway was $5 \mathrm{~m}$. (iii) A distance between a borehole mouth of the blasting borehole to the floor of the gateway was $1.2 \mathrm{~m}$. (iv) An inclination of the blasting borehole should meet the borehole drilled in the seam as the principle. The borehole at the top level of the sidewall should be about $24^{\circ}$ and the low level should be in horizontal level. (v) The diameter of the blasting borehole would be $42 \mathrm{~mm}$. (vi) A charge weight would be $8.0 \mathrm{~kg}$, and (vii) the borehole sealed length would be $4 \mathrm{~m}$.

(4) Prevention Effect. During the drilling in the coal mass, the cutting value size from the borehole would be in a positive related relationship to the stress size of the coal. Figure 11 is a comparison diagram of cutting values before and after the blasting pressure released; the average reduction was about $32 \%$, the seam stress was obviously reduced, and the burst danger degree was reduced.

By the end of this paper, the mineable length of the coal mining face was safely completed with the mining operation.

\subsubsection{Prevention of Concentrated Dynamic Load-Type Rockburst}

(1) Analysis on Burst Start-Up Load Sources. In no. W1143 fully mechanized coal mining face of Kuangou Mine in China, the mining seam thickness was $3 \mathrm{~m}$ in average, inclination was $13^{\circ}$, and the seam depth was $317 \mathrm{~m}$. The direct roof of the seam was siltstone, and the average thickness of the roof was $9 \mathrm{~m}$. The direct floor was layered medium sandstone and the thickness was $5.2 \mathrm{~m}$. The bottom floor was grit stone and the thickness was $12.99 \mathrm{~m}$. The seam, roof, and floor all had a burst tendency and would have high horizontal stresses.

The north of the haulage roadway of no. W1143 working face was no. W1141 goaf area, and the south of the return 


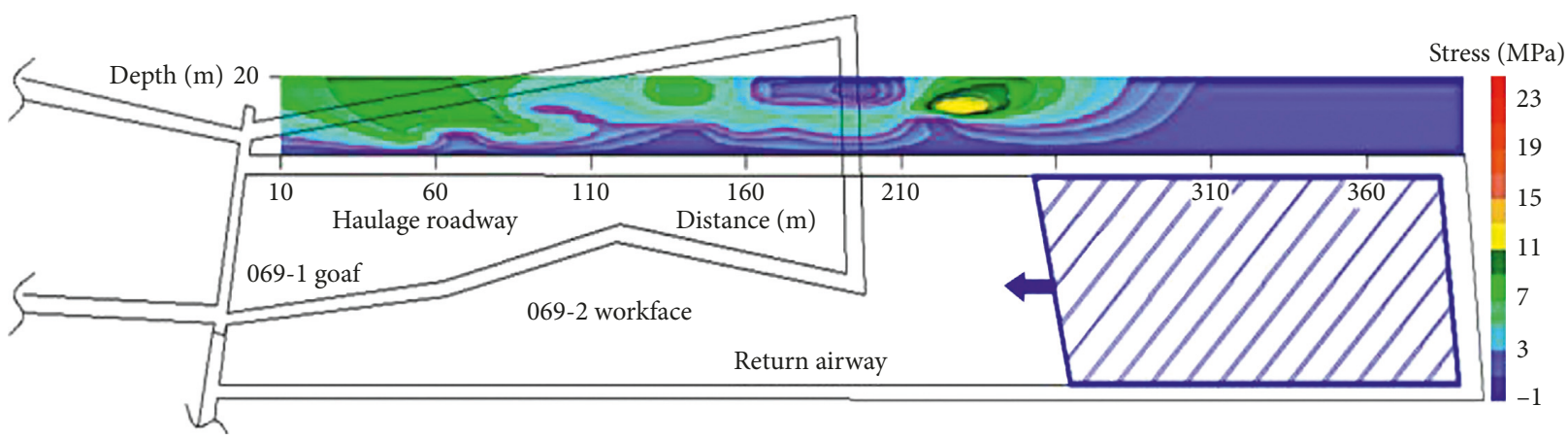

(a)

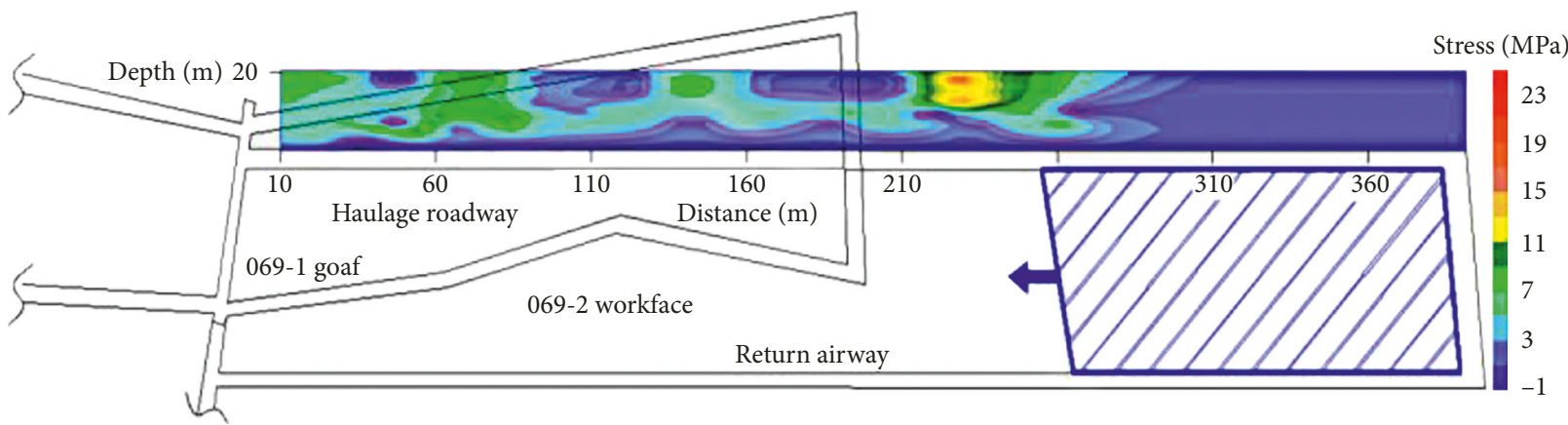

(b)

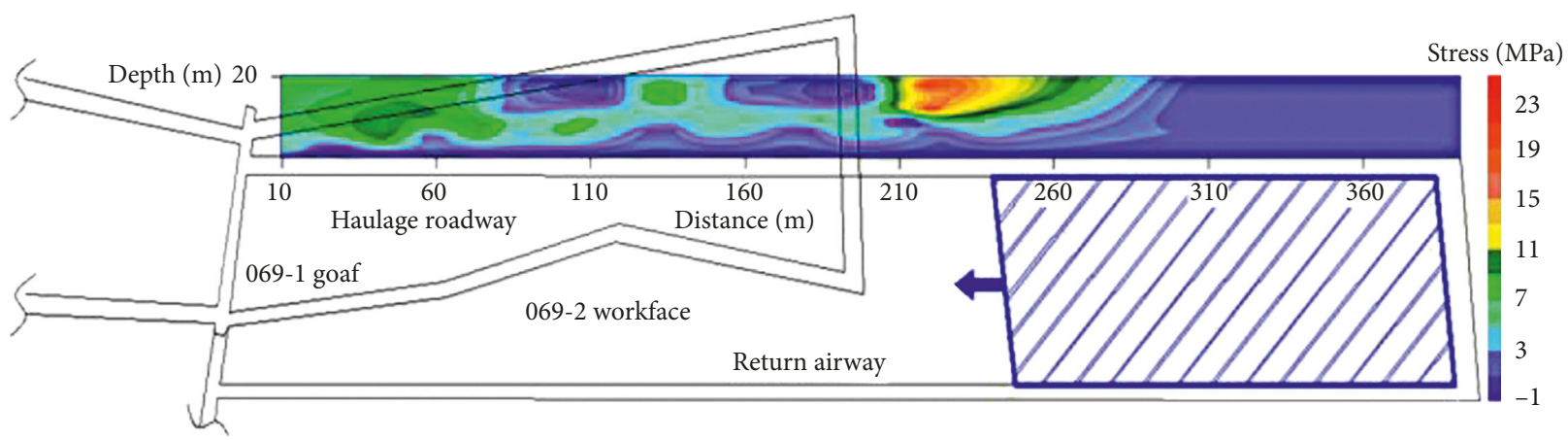

(c)

FIGURE 9: Stress nephogram of low sidewall in haulage roadway of coal mining face with different pushing rate. (a) Coal mining face pushed at $125 \mathrm{~m}$. (b) Coal mining face pushed at $137 \mathrm{~m}$. (c) Coal mining face pushed at $154 \mathrm{~m}$.

Coal seam
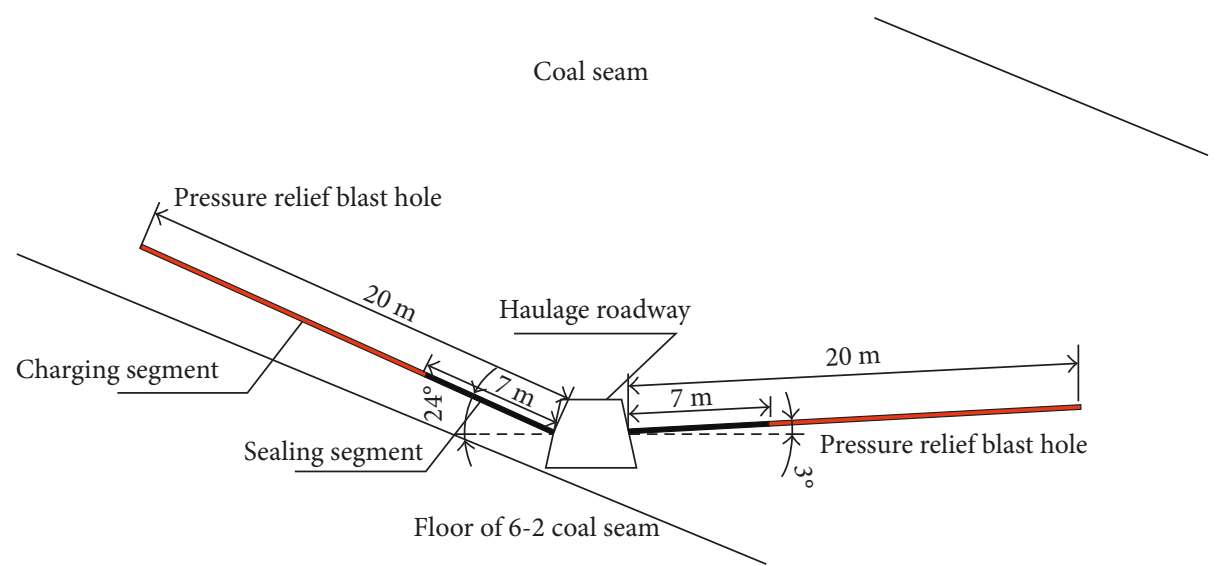

FIGURE 10: Engineering diagram of seam blasting and pressure releasing in gateway of no. 069-2 coal mining face. 


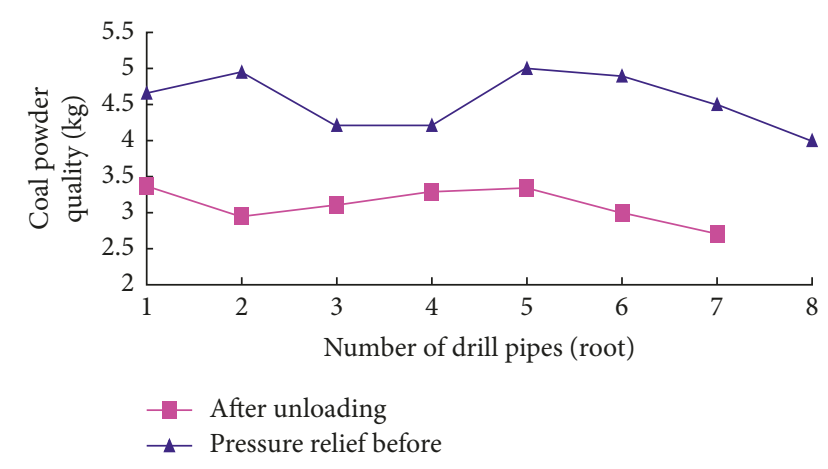

Figure 11: Comparison diagram of coal cutting values before and after blasting pressure released.

airway was an unexploited area. There was a coal pillar with a width of $30 \mathrm{~m}$ left between the two coal mining faces. In the mining process of no. W1143 coal mining face, several rockbursts occurred at the down end of the coal mining face, and the occurred location is shown in Figure 12. The site failure is shown in Figure 13. The down end of no. W1143 coal mining face in Kuangou Mine was in the burst moment. Although the coal mining face was mainly controlled by the roof concentrated dynamic load, the burst start-up in essence was the static load concentration at the front of the coal wall by the internal cause. The external dynamic load played a promotional role, the floor and coal wall were only the carrier of the energy transmission and releasing and were the location of the rockburst behavior. Thus, the late rockburst monitoring and prevention considered the two load sources.

(2) Monitoring and Measuring of Rockburst Source. (a) Monitoring and measuring of concentrated dynamic load source: according to the hard roof above no. W1143 coal mining face, a microseismic monitoring and measuring was applied. The layout of the microseismic station was as shown in Figure 13. In the haulage roadway of no. W1143 coal mining face, there were three stations: no. 1 , no. 2 , and no. 3 stations. In the return airway, there were two stations: no. 4 and no. 5 stations. In the return airway of no. W1145 coal mining face, there were three stations: no. 6 , no. 7 , and no. 8 stations.

On June 12, 2011, three major microseismic incidents occurred at 19:34, 23:13, and $23: 30$, respectively, in no. W1143 coal mining face. Three roof breakings were positioned by the microseismic monitoring and measuring system. In the $(X, Y$, and $Z)$ coordinate system, the sequences were $(715,8936$, and 1347$),(686,8984$, and 1340$)$, and $(741,8856$, and 1352) (the vertical elevation of the coal seam was $1320 \mathrm{~m})$, and the energy was $4 \times 10^{4} \mathrm{~J} / \mathrm{m}^{3}$, $1 \times 10^{4} \mathrm{~J} / \mathrm{m}^{3}$, and $64 \times 10^{3} \mathrm{~J} / \mathrm{m}^{3}$ individually (Figure 14). In 19:34 microseismic incident, the pushing bars of no. 14 to no. 20 hydraulic powered supports were vibrated in the coal mining face, miners were lifted by the floor, and the coal blasting sound of the coal wall was frequent and serious. It can be seen that the concentrated dynamic load on the working face had a significant influence on the disturbance and loading of the concentrated static load of the coal wall. (b) Monitoring and measuring of concentrated static load source: a borehole stress detector was installed in an advance scope of the coal mining face. With the advancing of the coal mining face, the borehole stress detector would record the coal stress conditions with the mining variation. The layout of the borehole stress detector is shown in Figure 15.

Three groups with 15 borehole stress detectors were set up. There were five borehole stress detectors set in the solid coal of the haulage roadway with a distance of $129 \mathrm{~m}$ to the coal mining face, five borehole stress detectors set in the coal pillar with a distance of $139 \mathrm{~m}$ to the coal mining face, and five borehole stress detectors set in the low level of the sidewall of the gateway. The depth of five boreholes in each group was $5 \mathrm{~m}, 7 \mathrm{~m}, 9 \mathrm{~m}, 11 \mathrm{~m}$, and $13 \mathrm{~m}$ individually, and the space between the boreholes was $5 \mathrm{~m}$ in average.

Based on the monitoring and measuring results of the borehole stress detectors in the seam, the advance support pressure influence scope of the coal mining face was $0-60 \mathrm{~m}$, the peak location was $13.9-16.75 \mathrm{~m}$, and the concentration coefficient of the advance support pressure was 2.87 in average. The depth of no. W1143 coal mining face was converted to a gravity stress of $7.92 \mathrm{MPa}$. Plus the stress concentration coefficient, the peak was $22.73 \mathrm{MPa}$. The uniaxial compressive strength of the seam measured in the lab was $28.80 \mathrm{MPa}$ in average. Thus, the accumulation degree of the concentrated static load in the coal wall was not sufficient.

(3) Rockburst Prevention. The analysis of the above showed that the single concentrated static load and the concentrated dynamic load of the coal mining face could not cause the burst start-up. The burst start-up condition was that the concentrated dynamic load occurred from the roof breaking would make disturbances and overlying to the static load. Thus, the rockburst prevention in Kuangou Mine should consider two load sources.

(i) Elimination of Concentrated Dynamic Load-Roof Breaking Blasting. From a $5 \mathrm{~m}$ location of the return airway in the coal mining face, each $12 \mathrm{~m}$ would set one blasting borehole (each 8 supports), the borehole would be set in the related roof at the front of the two supports, and there were 16 boreholes in total. The diameter of the borehole was $75 \mathrm{~mm}$, the depth of the borehole was $15.3 \mathrm{~m}$, and the horizontal along seam strike with an elevation angle of $60^{\circ}$. The charge length was $10.3 \mathrm{~m}$, the borehole sealed length was $5 \mathrm{~m}$, and charge density was $2.8 \mathrm{Kg} / \mathrm{m}$. From down end of the coal mining face, each two boreholes would be a group, the wiring method would be a series, and the blasting would a forward single ignition as shown in Figure 16.

(ii) Control of Concentrated Static Load Accumulation. A seam water injection could change the physical and mechanic features of the coal/rock, could reduce the burst tendency, and could fully eliminate burst capacity of the coal/rock. Seam water injection test was conducted in the down and upper gateways of no. W1143 coal mining face in Kuangou Mine. From the front of the coal wall of the working 


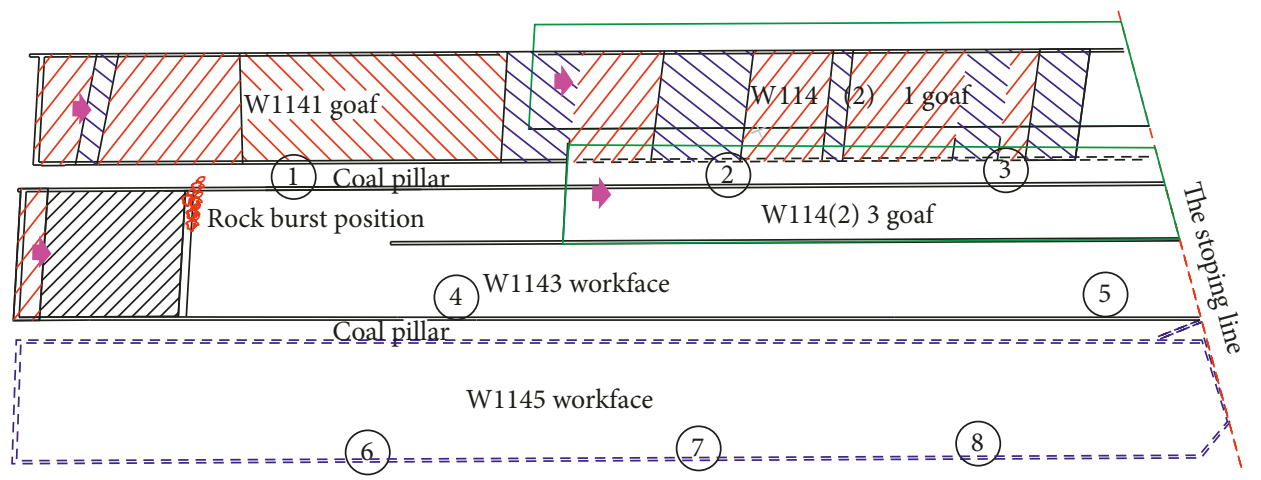

FIGURE 12: Location of coal mining face and layout of microseismic monitoring and measuring station.

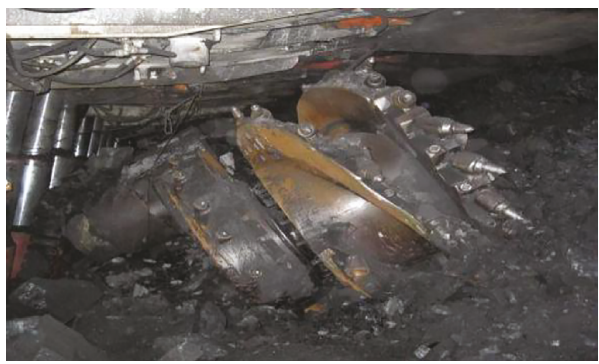

Figure 13: Coal mining face failure caused by rockburst.

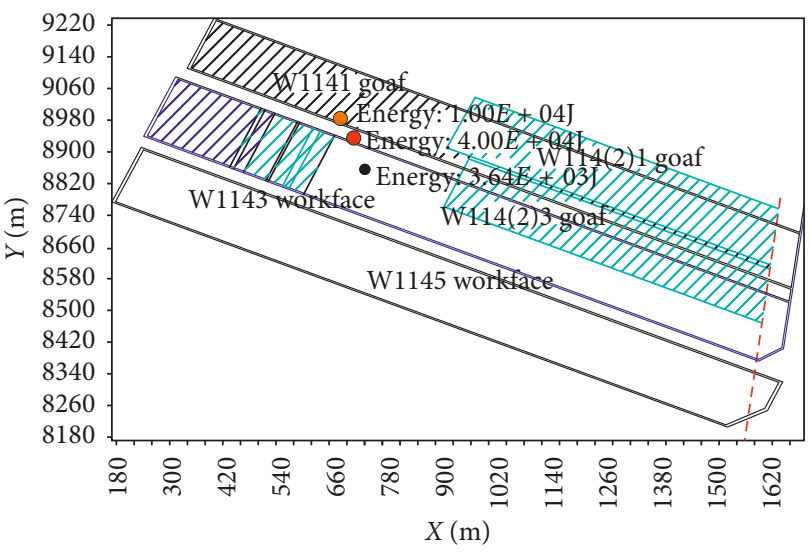

FIGURE 14: Roof breaking positioned by microseismic.

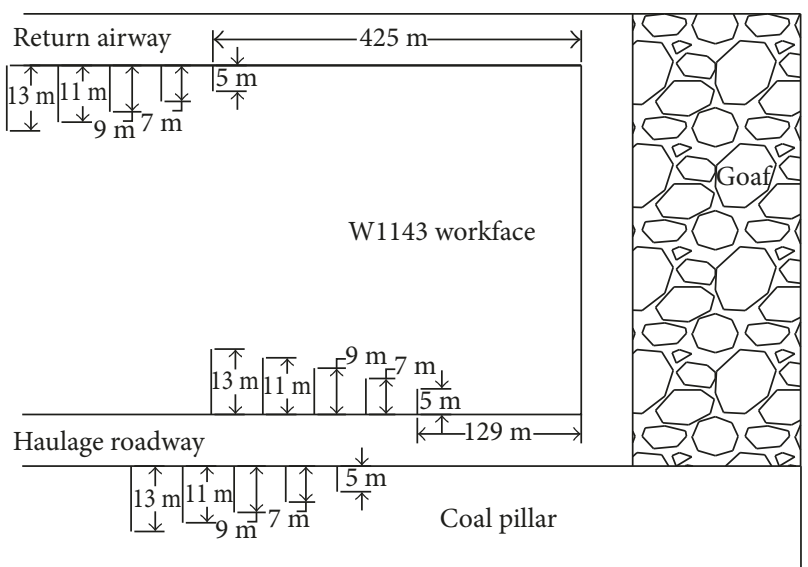

FiguRe 15: Layout diagram of borehole stress detector.

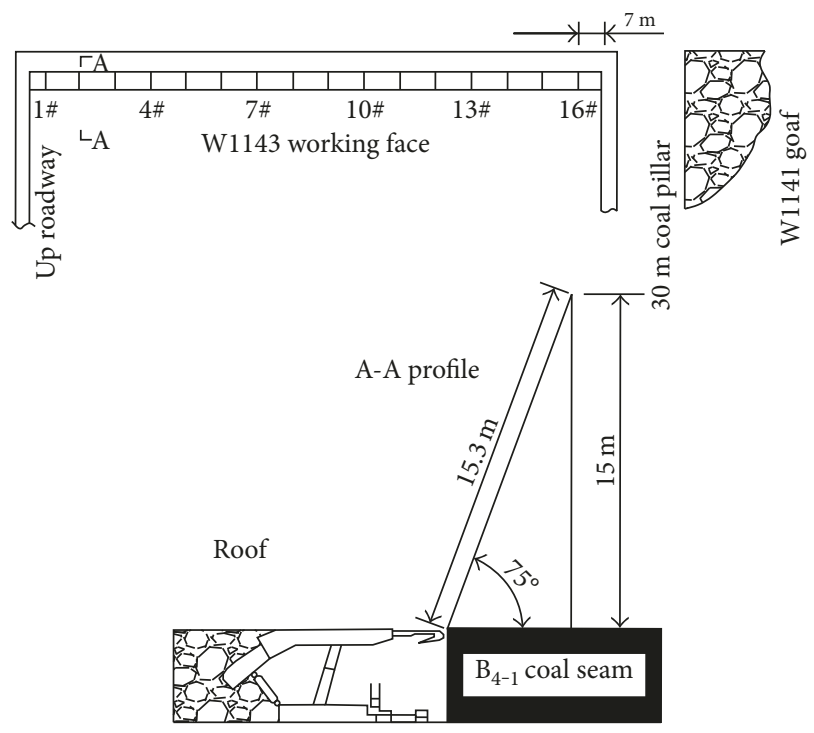

FIGURE 16: Borehole layout of roof breaking blasting. (a) Planar graph. (b) Profile.

face $40 \mathrm{~m}$, along the inclined direction of coal seam, the pore diameter was $75 \mathrm{~mm}$, the borehole depth in the haulage roadway was $100 \mathrm{~m}$, the borehole depth in the return airway was $50 \mathrm{~m}$, and the spacing between holes was $20 \mathrm{~m}$, which was located in the pressure relief chamber. The pressure of the water injection pump was controlled ranging from 5 to $10 \mathrm{MPa}$ and the water injection pressure was controlled when a certain water leakage from the coal wall.

Based on the water injection test conducted, a water injection time of a single borehole was determined as 6 days. Each 4 boreholes would be made as a group for the water injection. The water injection quantity of each group in the haulage roadway was $100 \mathrm{~m} \times 2.3 \mathrm{~m} \times 60 \mathrm{~m} \times 1.36 \mathrm{t} / \mathrm{m}^{3} \times 25 \times 10^{-3} \mathrm{~m}^{3}=469.2 \mathrm{~m}^{3}$. The water injection quantity of each group in the return airway was $50 \mathrm{~m} \times 2.3 \mathrm{~m} \times 60 \mathrm{~m} \times 1.36 \mathrm{t} / \mathrm{m}^{3} \times 25 \times 10^{-3} \mathrm{~m}^{3}=234.6 \mathrm{~m}^{3}$. The water injection plan is shown in Figure 17.

(4) Prevention Effect. According to the analysis results on the rockburst start-up load source in no. W1143 coal mining face, source monitoring and measuring on the concentrated static load and concentrated dynamic load and the source 


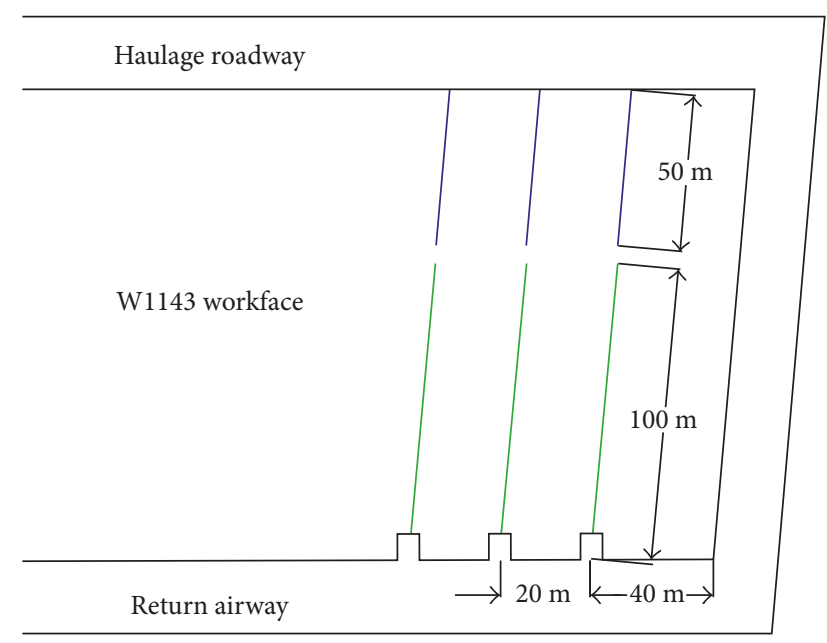

FIGURE 17: Plane section layout diagram of water injection in coal mining face.

prevention were conducted in the coal mining face. Based on the source monitoring and measuring results of the rockburst, a roof cutting blasting and seam water injection and blasting were conducted mainly in no. W1143 coal mining face. The site practices showed that the roof treatment measures would effectively reduce the coal wall stress and energy concentrated degree caused by the hard suspended roof and could reduce the disturbance of the large area suspended roof falling to the coal wall. The strike length of the coal mining face was $1500 \mathrm{~m}$ and was successfully completed.

\section{Conclusions}

(1) The rockburst was an event occurred process and not a phenomenon, and the rockburst occurred process includes a burst start-up stage, burst energy transmission stage, and rockburst behavior stage.

(2) Accumulation of the concentrated static load in the mining surrounding rock near the coal mining face was a joint internal cause of two types of burst startup. The possible burst start-up zone was the maximum zone of stress peak in the limit equilibrium zone. The burst start-up in the coal mining face and gateway actually was a static load concentration in the limit equilibrium zone and was an internal cause. The external dynamic load could play a promotive role. The floor and coal wall were only the carriers to transmit and release the energy and were the rockburst behavior location.

(3) The rockburst prevention of the mining and driving space was respectively conducted to the source monitoring a measuring on the concentrated static load, concentrated dynamic load source, and the source control to realize a correlation of the mechanism, monitoring, and prevention. The practices showed that the new understanding on the rockburst and the prevention method were feasible and the effect was good.

\section{Conflicts of Interest}

The authors declare that there are no conflicts of interest regarding the publication of this paper.

\section{Acknowledgments}

This work was supported by the State Key Project of Research and Development Plan of China (2017YFC0804204) and the National Natural Science Foundation of China (51704155).

\section{References}

[1] J. Ptáček, "Rockburst in Ostrava-Karvina coalfield," Procedia Engineering, vol. 191, pp. 1144-1151, 2017.

[2] B. G. He, R. Zelig, Y. H. Hatzor et al., "Rockburst generation in discontinuous rock masses," Rock Mechanics and Rock Engineering, vol. 10, pp. 1-22, 2016.

[3] L. M. Dou, Z. L. Mu, Z. L. Li et al., "Research progress of monitoring, forecasting, and prevention of rockburst in underground coal mining in China," International Journal of Coal Science and Technology, vol. 1, no. 3, pp. 278-288, 2014.

[4] L. Driad, F. Lahaie, and M. Alheib, "Seismic and geotechnical investigations following a rock burst in a complex French mining district," International Journal of Coal Geology, vol. 64, pp. 66-78, 2005.

[5] A. Tajduś, J. Cieślik, and K. Tajduś, "Rockburst hazard assessment in bedded rock mass: laboratory tests of rock samples and numerical calculations," Archives of Mining Sciences, vol. 59, no. 3, pp. 591-608, 2014.

[6] Z. L. Li, L. M. Dou, W. Cai et al., "Investigation and analysis of the rock burst mechanism induced within fault-pillars," International Journal of Rock Mechanics and Mining Sciences, vol. 70, pp. 192-200, 2014.

[7] A. T. Iannacchione and J. Zelanko, "Occurrence and remediation of coal mine bumps: a historical review," in Proceedings of the Mechanics and Mitigation of Violent Failure in Coal and Hard-Rock Mines, pp. 27-68, Norton, VA, USA, May 1995.

[8] P. P. Prochazka, "Application of discrete element methods to fracture mechanics of rock bursts," Engineering Fracture Mechanics, vol. 71, no. 4-6, pp. 601-618, 2004.

[9] S. V. Tsirel and N. V. Krotov, "Probability interpretation of indirect risk criteria and estimate of rock burst hazard in mining anthra cite seams," Journal of Mining Science, vol. 37, no. 3, pp. 240-260, 2001.

[10] L. M. Dou and X. Q. He, Theory and Technology of Rock Burst Prevention, China University of Mining andTechnology Press, Xuzhou, China, 2001, in Chinese.

[11] W. Cai, L. M. Dou, S. Y. Gong et al., "Quantitative analysis of seismic velocity tomography in rock burst hazard assessment," Natural Hazards, vol. 75, no. 3, pp. 2453-2465, 2015.

[12] G. Bräuner, Rockbursts in Coal Mines and Their Prevention, Balkema, Rotterdam, Netherlands, 1994.

[13] J. Litwiniszyn, "The phenomenon of rock bursts and resulting shock waves," Mining Science and Technology, vol. 1, pp. 243-251, 1984.

[14] M. Bukowska, "The rockbursts in the Upper Silesian Coal Basin in Poland," Journal of Mining Science, vol. 48, no. 3, pp. 445-456, 2012.

[15] P. Konicek, K. Soucek, L. Stas et al., "Long-hole destress blasting for rockburst control during deep underground coal 
mining," International Journal of Rock Mechanics and Mining Sciences, vol. 61, pp. 141-153, 2013.

[16] C. P. Lu, G. J. Liu, Y. Liu et al., "Microseismic multi-parameter characteristics of rockburst hazard induced by hard roof fall and high stress concentration," International Journal of Rock Mechanics and Mining Sciences, vol. 76, pp. 18-32, 2015.

[17] Z. L. Li, L. M. Dou, W. Cai et al., "Roadway stagger layout for effective control of gob-side rock bursts in the longwall mining of a thick coal seam," Rock Mechanics and Rock Engineering, vol. 49, no. 2, pp. 621-629, 2016.

[18] H. Lan, Q. X. Qi, and J. F. Pan, "Analysis on features as well as prevention and control technology of mine strata pressure bumping in China," Coal Science and Technology, vol. 39, no. 1, pp. 11-15, 2011, in Chinese.

[19] Y. S. Zhao, Z. C. Feng, and Z. X. Chang, "The least energy principle of dynamical rock failure," Chinese Journal of Rock Mechanics and Engineering, vol. 21, no. 1, pp. 931-933, 2002, in Chinese. 


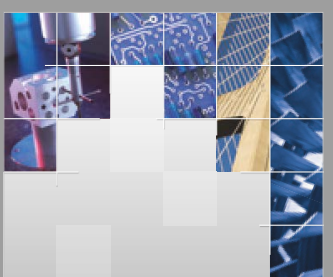

\section{Enfincering}
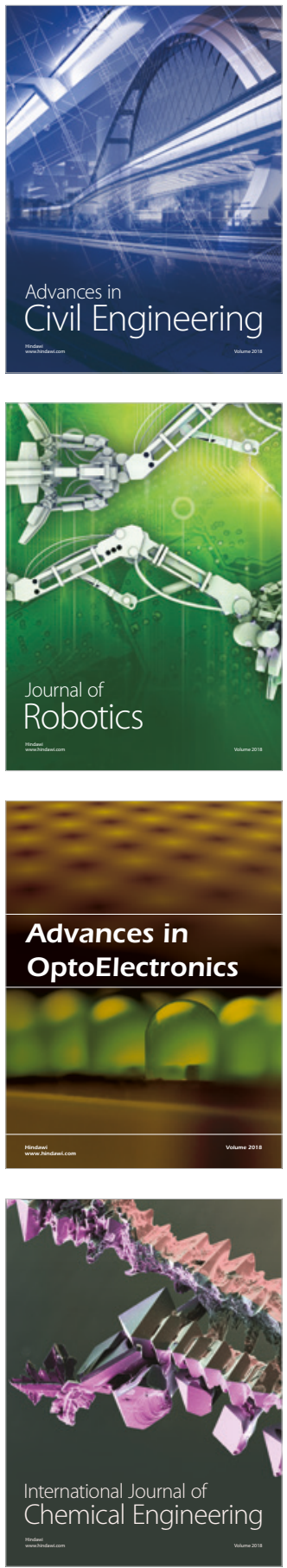

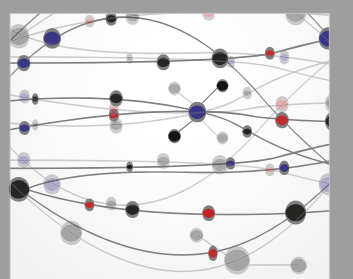

\section{Rotating \\ Machinery}

The Scientific World Journal

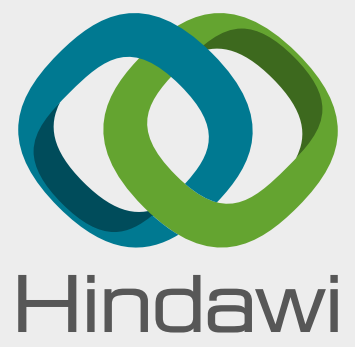

Submit your manuscripts at

www.hindawi.com
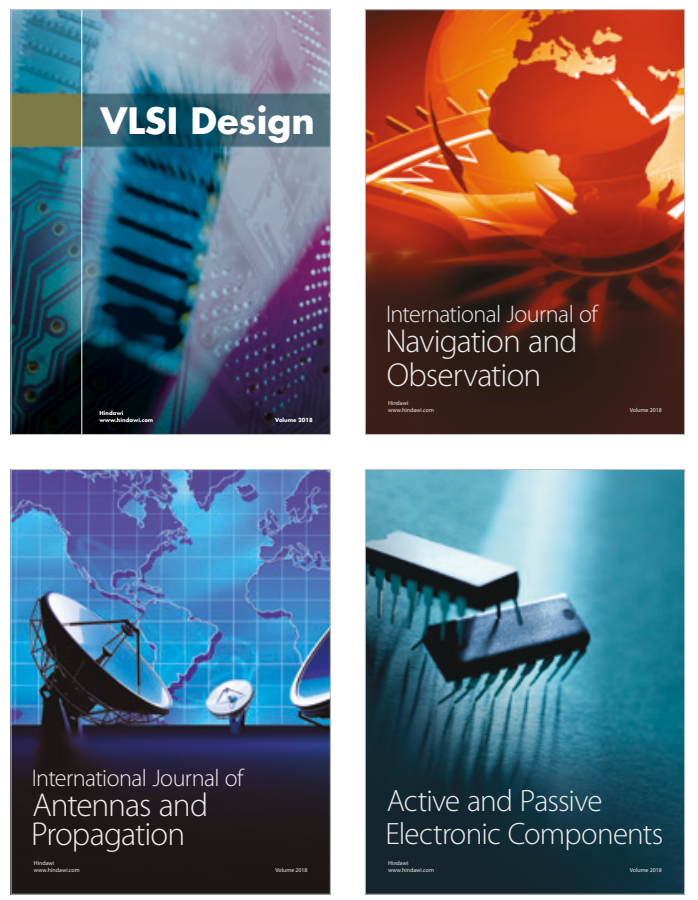
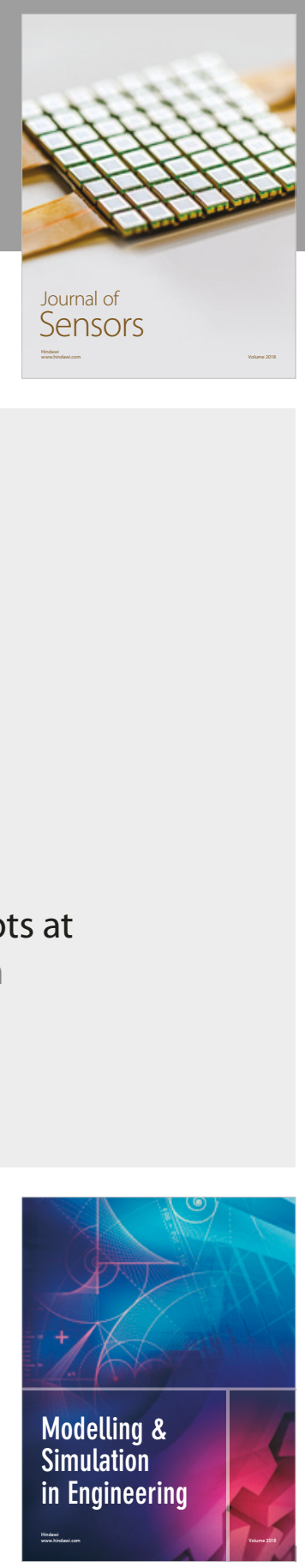

\section{Advances \\ Multimedia}
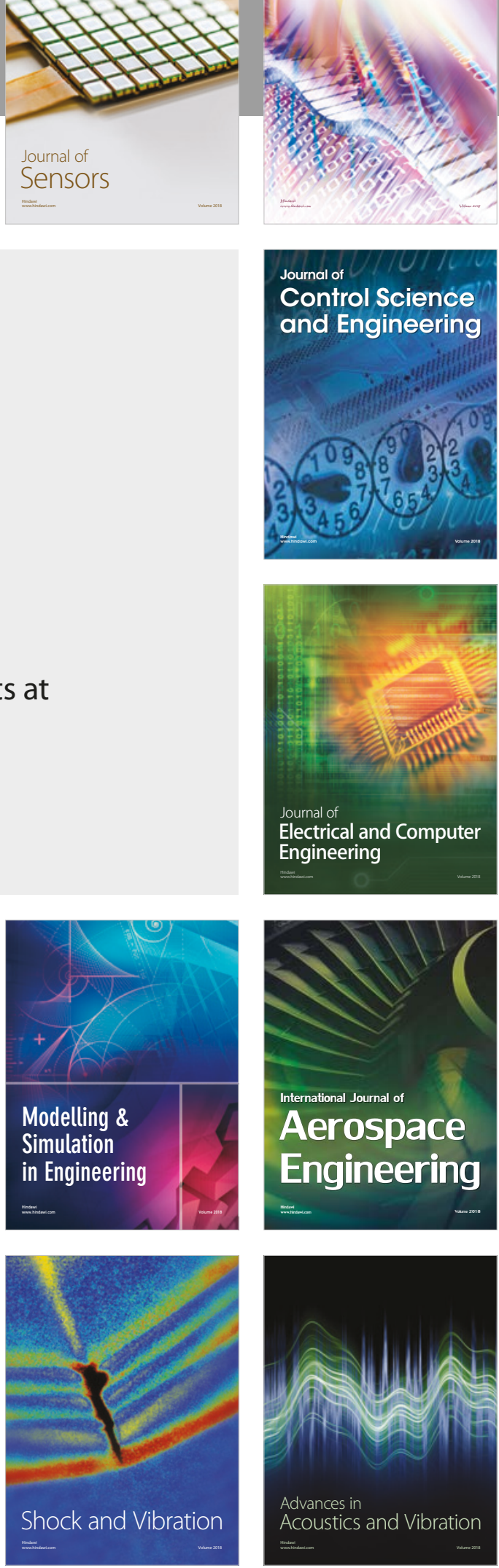